\title{
Prodigal Daughters. Stories of South African Women in Exile*
}

\section{Natalia Cabanillas ${ }^{* *}$}

Durante o apartheid na África do Sul (1948-1994), milhares de pessoas viram-se forçadas a abandonar o país, especialmente nos anos que seguiram o Massacre de Sharpeville (1960), e o Levante de Soweto (1976). ${ }^{1}$ Homens e mulheres saíram do país perante a possibilidade iminente de serem assassinados ou detidos, para manterem certa unidade familiar, ou com o objetivo de virar combatentes da guerrilha nos campos de treinamento dos países limítrofes, ou mesmo por vários desses motivos juntos. $\mathrm{O}$ livro Prodigal Daughters, escrito pela ativista sul-africana Lauretta Ngcobo, foca-se em histórias-memórias de mulheres que exilaramse durante a década de 60, e voltaram à África do Sul entre 1991 e 1995, durante a transição à democracia.

Um(a) sujeito(a) da história controvertido(a), um período complexo e uma experiência - o exílio - cheio de tensões. A tarefa não é simples: como escrever a história das mulheres sem que a própria escrita reduza os itinerários de vida aos cânones androcêntricos das disciplinas humanistas e científicas? De que

* Resenha de Ngcobo, Lauretta. Prodigal Daughters. Stories of South African Women in Exile. KwaZulu Natal University Press, África do Sul, 2012. Recebida para publicação em 22 de julho de 2013, aceita em 7 de agosto de 2013.

** Doutoranda em Sociologia, Universidade de Brasília - UnB.

nataliacabanillas@gmail.com

1 No Massacre de Sharpeville (21 março 1960), a polícia atirou contra uma manifestação pacífica contrária aos passes, ou controle de mobilidade da população não branca. Logo após desatou-se um processo repressivo, fazendo com que as principais lideranças fossem detidas ou exiladas e as organizações políticas foram banidas. O Levante de Soweto (1976) iniciou-se com um protesto estudantil contra o ensino em língua afrikáans, considerada a língua do opressor, e teve uma ampla solidariedade em vários bairros segregados ou townships. Imediatamente, o governo reforçou a repressão, razão pela qual milhares de adolescentes saíram para o exílio para se formar como combatentes. 
forma dar conta da vida das filhas pródigas descobrindo o seu excepcionalismo no cotidiano? Como abrir uma janela para olhar a multiplicidade de variáveis que afetaram uma geração de mulheres sem produzir homogeneizações? Pode-se narrar as tensões entre os e as ativistas dentro e fora da África do Sul sem contar uma história unívoca?

A primeira questão que quero colocar é que o exílio não foi senão uma das modalidades de deslocamento forçado imposto pela política de segregação, primeiro, e pelo apartheid desde 1948. A Lei de Terras de 1913 significou a espoliação de terras africanas em mãos da minoria branca, e com ela, a expulsão da população masculina jovem das áreas rurais, procurando dinheiro para pagar os impostos (Ngcobo, 2011:1); além disso, entre 1960 e 1990 calcula-se que 3.5 milhões de african@s foram removid@s violentamente das suas áreas de residência em cumprimento da Lei de Áreas por Grupos (1950), cuja finalidade era segregar racialmente os espaços de moradia (Worden, 1994); também milhares de pessoas procuraram salvar suas vidas, ou evitar a detenção nos insílios ou exílios.

O exílio sul-africano tem sido marcado, por um lado, pelos relatos épicos dos heróis guerrilheiros do Umkhonto We Sizwe ${ }^{2}$ (Ngcobo, 2011); e por outro lado, pela negação, desde que iniciaram-se as negociações da transição e a política para os e as ex-combatentes seria unicamente a de integrar-se nas South African Defense Force, contra quem até nesse momento tinham lutado (Rajes Pillay, apud Ngcobo, 2011:184). Múltiplas formas de viver $e$ transitar os exílios ficam fora dessas narrativas.

A interessante e escassa bibliografia sobre as mulheres na luta contra o apartheid tem se concentrado nos movimentos

\footnotetext{
2 ANC, siglas para African National Congress, foi o principal movimento de libertação na África do Sul. Fundado como organização cartista em 1912, virou movimento de massas nos anos 50; perseguido pelo regime, protagonizou boa parte da luta para derrubar o apartheid, as negociações para a transição $e$ encabeçou o primeiro governo democrático desse país quando, em 1994, Nelson Mandela foi eleito por maioria popular como o primeiro presidente negro. Até o dia de hoje, o ANC governa a África do Sul.
} 
dentro do país, principalmente em dois momentos históricos quando o sujeito "mulheres" interveio na política nacional com organizações (relativamente) autônomas, de alianças amplas $e$ demandas próprias: nos anos $50 \mathrm{com}$ a Federação de Mulheres Sul Africanas (Walker, 1993 e Wells, 1984) e seu protagonismo na luta contra o controle da mobilidade da população não branca; $e$ durante a transição nos 90s, quando entra em ação a Coalizão Nacional de Mulheres, integrada pelas mais variadas forças políticas, construindo uma agenda de direitos e reclamos das mulheres e pressionando para sua inclusão nas negociações para a democracia (Hassim, 2006; Britton e Fish, 2009; Gasa e Sutner, 2007). Dita bibliografia as retrata participando na cena comunitária, aparentemente despolitizada, nos movimentos sindical, estudantil, nas federações nacionais ou regionais de mulheres, nos movimentos de libertação, nos partidos políticos $e$ na guerrilha.

Existem poucos estudos abrangentes sobre mulheres ativistas nos anos 60. Portanto, o livro preenche um vazio na produção de conhecimento, contribuindo com um excelente material para a análise das tensões de gênero na militância contra o apartheid. Devido à repressão, a documentação e os registros são escassos e fragmentários, e os métodos da história oral e a memória são a forma quase unívoca de reconstrução histórica. Em consonância, Prodigal Daughters é um livro formado por dezessete relatos autobiográficos de mulheres sul-africanas brancas $e$ não brancas, a maioria delas profissionais, ${ }^{3}$ todas elas mães, pertencentes ou não a algum movimento de libertação, tendo nascido no exílio ou saído pela perseguição à ela mesma ou a algum familiar, com experiências e roteiros diversos de exílios em países africanos e não africanos.

Assim, os exílios seriam mais um cenário da luta contra o apartheid, onde o movimento de mulheres do ANC perde

\footnotetext{
3 Isso não significa que tivessem uma origem de classe média alta, já que a maioria delas conseguiu estudar somente no exílio com ajuda do movimento de libertação ao qual pertenciam.
} 
autonomia, ao ser impedido de manter a Liga de Mulheres, e é levado a criar a Seção de Mulheres, dependente do Conselho Executivo Nacional daquela organização (Hassim, 2005). E, ao mesmo tempo em que as lideranças no exilio tiveram maior contato com o feminismo internacional, tinham poucas possibilidades de ter relações diretas com a realidade da luta dentro do país (Hassim, 2005). As tensões emergiram quando as lideranças voltaram à África do Sul, depois do levantamento da proibição do ANC e do PAC ${ }^{4}$, em 1990.

O livro Prodigal Daughters foca-se em experiências atravessadas por tensões: a decepção com os movimentos de resistência; as dificuldades para a sobrevivência; as separações dos filhos, de amigos, parceiro ou família; a distância entre a experiência fora e dentro do país para as práticas políticas; a obediência aos movimentos; a impossibilidade de sustentar uma vida familiar e uma mínima rotina; as dificuldades da integração, da discriminação e o sentimento permanente de nostalgia e de não pertencimento. Todas temáticas polêmicas, intelectual $e$ politicamente, e que podem ser colocadas nos subterfúgios dos relatos em primeira pessoa que - até certo ponto - desafiam os limites da escrita acadêmica. Cronológicos, mas não lineares, os relatos escapam de focar-se unicamente nas lideranças femininas que foram bem sucedidas nos ambientes masculinizados da luta. O livro tem por virtude dar conta dos debates feministas mais atuais sem precisar referir-se explicitamente a eles, deixando à leitora o prazer de fazer uma leitura intertextual livre.

A autora (editora) coloca-se no texto em baixo da mesma lente crítica que o resto das narradoras. Não por se apresentar como tal numa introdução ou prefácio, mas por incluir a sua própria narração de exílio exatamente no mesmo formato que as demais. Estabelece, assim, uma relação de igualdade: situa-se tão sujeito como objeto, dando conta do chamado "conhecimento localizado" (Haraway, 1988; Harding, 1998). Dessa forma, consegue

4 O PAC - Pan African Congress - foi outro dos principais movimentos de libertação, de orientação pan africanista, que surgiu em 1959 como cisão do ANC. 
abrir mão do olhar onipresente explicativo ou racionalizador das experiências das outras (Berkin, 2012; Katmeier, 2012, Rufer, 2012). Como resultado, as narrativas não são generalizáveis, oferecendo uma resolução prática para prescindir dos conceitos universais, aspecto mais do que debatido dentro da academia e da política feminista (Mohanty, 1983). A escrita das atividades políticas não vem separada dos problemas considerados domésticos, preocupações e medos; mais do que em qualquer outro texto sobre o ativismo de mulheres na África do Sul, as emoções formam parte da história com letra maiúscula. Assim, longe de ser um agregado a história oficial, uma versão feminina da história androcêntrica, ou de reproduzir a épica militante, Lauretta Ngcobo, consegue mostrar outra forma de entender a história, suas ambiguidades e suas contradições. Talvez por esse motivo, o livro tenha uma introdução para contextualizar a história sulafricana, porém não possui nenhuma nota, parágrafo ou capítulo de conclusão. Como a História sem garantias tão presente nos estudos pós-coloniais, as narrações não têm uma palavra final, senão caminhos abertos e incertos.

Poderia acrescentar que a autora resolve alguns desafios centrais da escrita feminista: contar com as vozes das mulheres, seus pontos de vista e suas necessidades, literalmente em primeira pessoa, sem anulá-los no processo da autoria; não abolir seus interesses, preocupações e prioridades na edição das entrevistas; não impor o ponto de vista da pesquisadora, e por sua vez, dar o espaço suficiente para que o objeto de estudo continue sendo sujeito na escrita (Mies, 1998). Em outros termos, procurar caminhos que evitem que o exercício da escrita seja um processo de objetivação ou coisificação dos sujeitos.

Embora os exílios do apartheid pudessem ser considerados relatos do horror, as autoras em nenhum momento da escrita vitimizam-se. Pelo contrário, são ativas criadoras de estratégias políticas, com quotas importantes de poder e decisão sobre suas vidas. As suas identidades vão muito além (ou contrárias) a elas se colocarem como um produto do poder, do racismo o do sexismo, embora tenham nascido em um dos regimes com maior 
desenvolvimento da engenharia social para o controle $e$ a exploração da população. Como bem sinalizaram Cherryl de la Rey, Amina Mama e Zine Magubane (1997), as experiências de racismo e opressão não necessariamente criam patologização; podem gerar resiliência. As narrações que compõem o livro Prodigal Daughters são um bom exemplo disso. Uma conclusão desafiadora para os estudos de gênero e de memória centrados na vitimização, no trauma ou na impossibilidade da palavra.

Sem que Lauretta Ngcobo apresente como tal o tema, a narração de cada mulher exilada mostram uma prática de maternidade particular, e majoritariamente subordinada ao compromisso político. As dezessete histórias de vida dão muitos elementos para avançar no debate sobre o caráter conservador, ou não, do maternalismo sul-africano, podendo estabelecer uma nítida diferença entre a defesa política da maternidade e seu exercício real.

Poderia se objetar o grau de representatividade das narrações, sendo as mulheres que escrevem seus depoimentos no livro majoritariamente militantes urbanas, centradas em grande medida na família nuclear monogâmica e pouco nas relações comunitárias, e cujo mundo restringe-se à sociedade dos vivos (ausências que chamam a atenção no caso das mulheres africanas). Não obstante, a pretensão de ser representativo é ausente no livro, cujo título, de fato, sublinha o caráter excepcional, mais que majoritário, das vidas das filhas pródigas. Por um lado, pela alusão à história bíblica daquela que sem seguir as regras acaba no caminho certo; e, por outro lado, por chamar de filhas num país onde as grandes lideranças femininas são apelidadas como mães da nação.

A ausência da voz onipresente e racionalizadora (portanto, superior), nos deixa algumas perguntas sem resposta, concernente aos procedimentos metodológicos utilizados, tais como: se poderíamos considerar Prodigal Daughters como um livro de multiautoria, se os relatos foram ou não organizados pela autora, se foram editados ou se são produto de entrevistas. Isso não oblitera o fato de que as narrações das Prodigal Daughters têm, 
sem dúvida, muito que dizer sobre a história da África do Sul, as experiências das mulheres na luta contra o apartheid e também sobre os caminhos metodológicos criativos para um olhar africano e feminista nos estudos de gênero e memórias.

\section{Referências bibliográficas}

BRITTON, Hanna e FISH Jeniffer. Engendering Civil Society in Democratic South Africa. In: BRITON, Hanna; FISH, Jennifer e MEINTJES, Sheila. Women ativism in South Africa. Working across divides. University of KwaZulu Natal Press, África do Sul, 2009, pp.1-42.

CEJAS, Mónica Inés, Creating a women's political space within the anti apartheid movement of 1950s: the case of the Federation of South African Women (1954-1963), Teses de doutorado, Relações internacionais, Tsuda College, Japón, 2004.

CORONA Berkin, Sarah. Notas para construir metodologías horizontales . In: BERKIN, Sarah Corona e KALTMEIER, Olaf. En diálogos. Metodologías horizontales em Ciencias Sociales y Culturales. Gedisa, Barcelona, 2012, pp.85-109.

De la Rey, Cheryl, A. Mama e Z. Magubane. Beyond the masks. Agenda 32. Durban, 1997, pp17-23.

DE LA REY, Cheryl. Introduction: South African feminism, race and racism. Agenda 32, Durban, 1997, pp6-10.

GASA, Nomboniso e Raymond SUTnER (ed.), Women in South African History. Basus'iimbokodo, Bawel'imilambo/They remove boulders and cross rivers. El Cabo, Sudáfrica, HSRC Press, 2007.

GovendER, Pregs. Breaking the silence. Women's national coalition. Agenda n 16, Durban, 1993, pp.42-43.

HARAWAY, Donna. Situated Knowledges: The Science Question in Feminism and the Privilege of Partial Perspective. Feminist Studies, vol. 14, n 3, 1988, pp.575-599.

HARDING, Sandra. Existe un método feminista? In: BARTRA, Eli (comp). Debates en torno a una metodología feminista. Universidad Autónoma Metropolitana- Xochimilco, México, 1998, pp.2-15. 
HASSIM, Shireen. Women's organization and democracy in South Africa. Contesting authority. South Africa, KwaZulu University Press, 2006.

KALTNEIER, Olaf, Hacia la descolonización de las metodologías: reciprocidad, horizontalidad y poder. In: BERKIN, Sarah Corona $e$ KALTMEIER, Olaf. En diálogos. Metodologías horizontales em Ciencias Sociales y Culturales. Gedisa, Barcelona, 2012, pp.25-54.

KROG, Antjie, MPOlWeni, Nosisi y RATEle, Kopano. There was this Goat. Investigating the Truth Commission Testimony of Notrose Nobomvu Konile. University of KwaZulu Natal, África do Sul, 2009.

MIES, Maria. Investigación sobre mujeres o investigación feminista? El debate en torno a la ciencia y la metodología feminista. In: BARTRA, Eli (comp.). Debates en torno a una metodología feminista. Universidad Autónoma Metropolitana- Xochimilco, México, 1998.

MOHANTY, Chandra Talpade Bajo los ojos de occidente Academia Feminista y discurso colonial. In: NAVAZ, Liliana Suárez \& HERNÁNDEZ, Rosalva Aída (eds.). Descolonizar el Feminismo: Teorías y Prácticas desde los Márgenes, 2008, pp.112-162.

NDEBELE, Njabulo, The cry of Winnie Mandela, David Philip Publishers, África do Sul, 2004.

RUFER, Mario. "El habla, la escucha y la escritura. Subalternidad y horizontalidad desde la crítica poscolonial" In: BERKIN, Sarah Corona e KALTMEIER, Olaf. En diálogos. Metodologías horizontales em Ciencias Sociales y Culturales. Gedisa, Barcelona, 2012, pp.55-81.

SCANLON, Helen. Representation and Reality. Protraits of Women's lives in the Western Cape 1948-1976. HSRC, Cape Town, 2007.

WALKER, Cherryl. Women and Resistence in South Africa, Onyx Press, Londres, 1982.

WeLlS, Julia. We now demand: the History of Women's Resistance to Pass Laws in South Africa. Witwatersrand University Press, Johannesburgo, África do Sul, 1993.

WILDERSON, Kamogelo Lekubu. The Women's Convention. Change in social practice. Agenda n 36, Durban, 1997, pp.68-71. 